\title{
The Shortfall in Development Investment: a comment on Jayawardena's proposal
}

\author{
Alain Dangeard
}

\section{The Proposal}

The events of the last part of 1982 (Mexico's neardefault) have confirmed earlier apprehensions concerning the capacity of the international private banking system to continue supporting the developing countries' growing balance of payments deficits. Ambassador Jayawardena has dwelt clearly on some of the reasons for this dead-end: servicing costs have increased as a result of higher interest rates, while the capacity to reimburse has been impaired by declining export earnings. Recent interventions by official institutions are designed to ward off the worst, and to save the main international banks from collapsing under the accumulation of major defaults by borrowing countries. But these are temporary measures: unless economically profitable development takes place in the borrowing countries, debts will not be reimbursed.

Jayawardena's article emphasises the necessary solidarity between the oil exporting countries, the industrialised countries and the oil importing developing countries. Much has been said to underline this solidarity, but little has been done to transform it into an active policy. Many schemes have been advanced to try to induce surplus countries to commit their reserves to longer term loans, thus overcoming the present fragility of the recycling mechanism which is based essentially on liquid assets. The developing world needs to invest on a long term basis; short term loans or even the middle term maturities of the euromarket ( 7 to 8 years) will not satify their investment requirements.

Ambassador Jayawardena recalls one scheme advanced by the Commonwealth Secretariat, and another known as the Gutowski/Roth plan. Both try to set up some form of guarantee by the industrialised countries, so that OPEC assets on loan to less developed countries (ldcs) would be adjusted for inflation or exchange risks, and would provide, in return, a long term arrangement on the price of oil. Such ambitious mechanisms are considered implausible politically, and difficult to negotiate for lack of a proper international forum broad enough to encompass all the problems that would arise.
Instead, another approach, more limited geographically at the European level, is suggested by Jayawardena. It consists of:

- a unilateral offer by the EEC to introduce annually a certain volume of inflation-indexed securities to OPEC surplus subscribers, provided OPEC shows restraint in the annual percentage increases of the oil price. Part of the proceeds would be made available to ldcs by specially created institutions;

- a reciprocal offer by surplus OPEC countries to convert oil price increases into concessional loans to oil importing developing countries. 'The minimum volume of inflation-indexed securities could always be equated to the concessional financing burden so assumed by OPEC surplus countries'.

Details of this scheme matter less than its spirit: it tries to make interdependence work in practice by providing each partner with an appropriate mix of incentives. The maintenance of Third World purchasing power and credit worthiness benefits both the EEC and OPEC; OPEC derives a significant measure of protection of its assets from the new instrument offered by the EEC; restraint in the long term price increases of oil is of value to the EEC and to the ldcs.

It is easy to find many drawbacks in such a plan; the most obvious difficulty lies in trying to reach intergovernmental agreements to put the system into practice. But there are deeper objections.

How would the EEC countries manage the funds received from OPEC in exchange for the guaranteed securities? No institution could ever commit itself to protect such securities against inflation and exchange risks. Undoubtedly, the fact that OPEC would accept longer term maturities than those of assets made available to private banks would be a tremendous advantage on present recycling practices. As a result better management of the reinvested funds would be possible. But there is no reason why such an institution, by itself, would channel automatically the funds collected into profitable portfolios of equity or other assets in ldcs. Indeed, regardless of the liquidity risk of the present recycling mechanism through 
private banks, one may wonder what part of the $\$ 500$ bn or so of $1 \mathrm{dc}$ 's debts has been used for sound development investment, and what part has been used merely for day to day consumption or in operations with little prospect of ever producing a positive return. Unless the interested partners devote more attention to the investment needs and the return prospects of such investments in ldcs, it is doubtful that enough progress will be achieved towards a durable solution to the present financial impasse.

Another weakness of Ambassador Jayardena's suggestions is to leave the developing countries in a passive role as mere recipients of loans, without enough participation in decision-making, in particular in the decision concerning the use of the reinvestible funds received by the EEC institution against OPEC assets.

Nevertheless, it would be regrettable to overlook altogether this type of proposal. Since the governments of the West have little choice but to come to the rescue of their banks exposed in international lending to ldcs concerted initiatives should aim at correcting earlier errors in the recycling mechanisms, and not at perpetuating the established practices which are largely responsible for the present crisis. One should always keep in mind that euro-market conditions are ill-suited to the long term development strategies of ldcs; that the ratio of aid to commercial finance has deteriorated beyond any reasonable figure; and that the a mount of direct equity investment in ldes is a very small percentage of all recycled funds, probably no more than 5 per cent to 10 per cent.

One should face seriously the question of the shortfalls in suitable instruments for development investment. It has been noted that 'the largest part of OPEC surplus funds is in bank deposits, short term financial instruments, top rated corporate bonds, long term government securities, government to government loans and loans to international organisations. Only a relatively small portion has reportedly gone into equity investment in the industrial countries and comparatively smaller to non-oil 1dc' [Amuzegar 1982]. Given the deteriorating conditions of 1982, there seem to be only two approaches to deal with the present financial crisis.

On the one hand, there are global schemes, arranged between governments and international organisations, to provide the indebted ldcs with the necessary finance to continue to service their debts. But unless schemes attempt also to treat the financing of development investments, the crisis itself will remain self perpetuating.

On the other hand, one may advocate relying on private direct investment to finance the agricultural and industrial needs of the ldcs. But past experience is not very encouraging. The obstacles against increasing direct investment by OPEC countries in the ldcs are formidable: there are reservations by the recipient countries as well as by the surplus countries; institutional barriers and economic risks are considered higher in ldcs; and OPEC countries may be even more sensitive to such risks than industrial countries, since their capital is not a forerunner to exports of management, technology or equipment. Nevertheless, such hurdles are not insurmountable. Unlike the global financial schemes, direct investment by a variety of international operators has the advantage of relying on decentralised initiatives. The conditionality of the IMF is no guarantee of appropriate dynamism in the recipient country, while direct investment is a good measure of the capacity of developing countries to set up and manage a viable development.

\section{An Alternative}

In a sense, Ambassador Jayawardena's proposal is an attempt to bridge these two approaches. The spirit which inspires it is a good recipe for new initiatives: interdependence; a unilateral gesture by the EEC during a period of 'soft oil market'; anticipation of a reciprocal answer from the surplus countries. What is suggested below is that this set of proposals could be rearranged to answer the criticisms that have been made both of global or regional schemes, and of direct investment. In Jayawardena's scheme, one European institution has the unenviable task of issuing inflation proofed instruments to surplus countries, and of reusing the collected funds in ldcs. Instead of attempting such a one-sided guarantee of assets, the institution could serve to promote the co-financing of risk capital ventures between operators from OPEC, from European countries and from ldcs. There would be a sort of 'umbrella' or triangular management of such co-financing, with a few simple rules of solidarity between participants.

The basis of such action would be the setting up in ldcs of sectoral priority programmes, or strategies where the potential for successful ventures appear large. Such priority programmes should be discussed between the participants, particularly in respect of the required technological training and institutional continuity necessary for their success. They should cover agricultural self-sufficiency, energy diversification, raw materials' contribution to development and industrial development in relation to local needs or international markets. ${ }^{1}$ Instead of starting from the

${ }^{1}$ Concerning industrialisation programmes, the discussion with EEC countries should attempt to promote joint development of new industries in Ides and modernisation of older industries in Europe with a view to maximising the growth of potential markets in ldcs, in Europe and elsewhere. Such joint investment would appear in many instances capable of promoting complementary interests. 
existing 'exportable' technologies of the industrial countries (the export credit approach), such programmes would start from the investment needs of the ldcs which are necessary for the success of a given strategy. When programmes are agreed upon, public and private investors would be invited to develop ventures to meet their objectives. The rules of solidarity would be known in advance: a political risk guarantee; 'performance' norms from the foreign investor; commitment by the 'host' government not to change the economic and administrative rules agreed upon when adopting the programme. It may also be desirable in some cases for part of the risk capital in such joint ventures to be covered by a "commercial guarantee': it might be called for, for example, in the case of energy diversification programmes that may be threatened in the short term by an unexpected fall in international oil prices, while the long term return of such diversification should not normally be affected.

A large part of the implementation of the ldcs' strategies would thus be left to private decentralised initiatives. Surplus country investors should be reassured by several features of the scheme: the association of risk-capital from developed and OPEC countries; the fact that ldc governments would themselves establish their objectives, so that there should be no reason to be afraid of offending their political sensitivity; the triangular formula, relating individual equity venture to a larger overall solidarity scheme. In practice, this 'umbrella' would thus operate on a sectoral basis, inviting projects and investors, and, following up the type of response it obtains from the participating countries in respect of the number of joint ventures, balance in the geographical origin of the investments, 'performance' etc. Should there be a lack of response from private groups, the institution should then try to promote implementation by itself raising supplementary funds and taking a part of the commercial risks. This triangular formula would be quite different from suggestions made in 1977 to mix capital from OPEC, technology from industrial countries and development projects from ldcs; here, each participant's indirect investment is on an equal footing.

One may observe that this type of public monitoring of privately executed programmes is not entirely new. In particular, a similar organisation was extensively used in the United States during and after the war to develop new technologies (nuclear, space). What would be novel in this new proposal is its international character as well as its application to ldc development needs. The basis of this approach is to consider the ldcs as equal participants, sharing in the conception, the risks and benefits of a series of programmes aimed at overcoming structural weaknesses in their economies. They would not be left alone to meet the conditions imposed by international financing institutions, but could initiate themselves the programmes and conditions which would make co-financing work in practice. Indeed, no attempt should be made to force on any country a particular framework for foreign investment. But, within such an 'umbrella' one may expect some of the mutual reservations (against 'profit' by foreign investors, against 'expropriation' by host countries) to be lessened, and eventually to disappear. Finally, the flexibility of such an initiative should allow for a step by step development, from an initial approach limited to one or two major programmes having a momentum of their own involving, for example, agriculture and energy. No large negotiations would be necessary since initial successes should attract, little by little, other governments, from a limited initial group of the ACP or other ldcs, OPEC, and the EEC.

\section{References}

Jahangir Amuzegar, 1982, The Energy Crisis, IBRD Paper EBD/82/127, supplement 1 . 